\title{
РЕАЛИЗАЦИЯ ПРАВА НА ТРУД ЛИЦАМИ, ОСУЖДЕННЫМИ К ЛИШЕНИЮ СВОБОДЫ
}

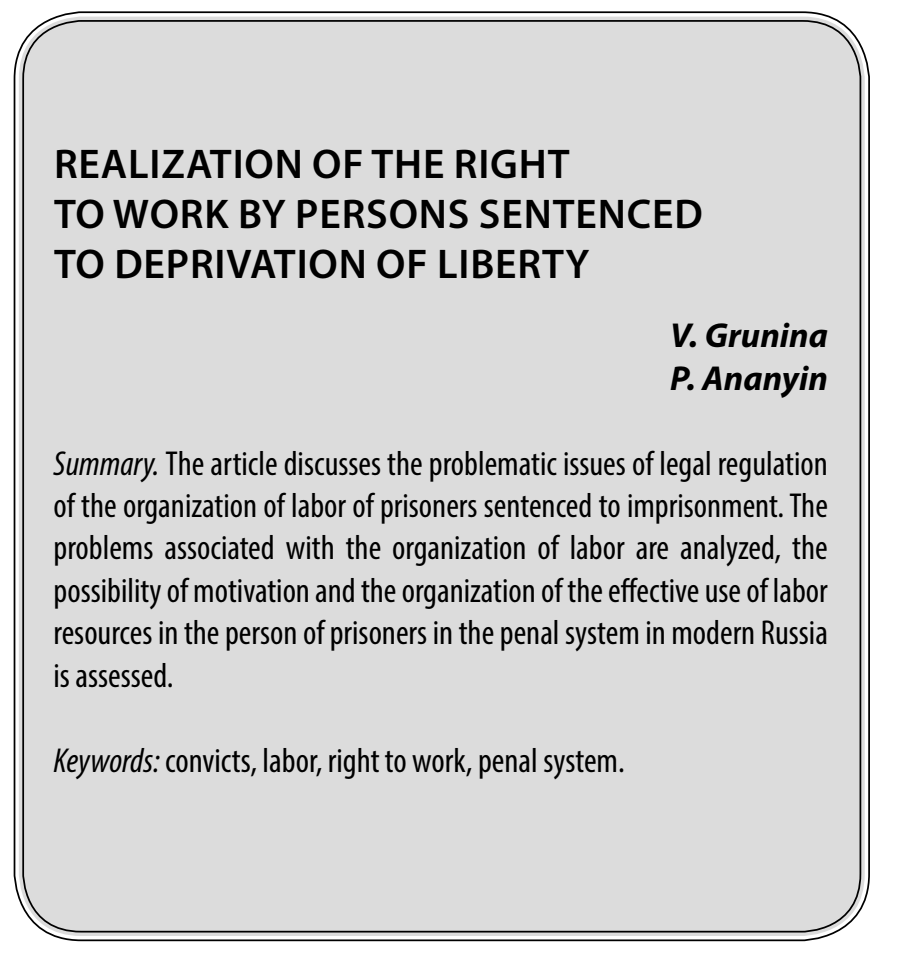

B опрос труда заключенных и лиц осужденных к обязательным и исправительным работам, как и прежде, остается в поле зрения правозащитников и вызывает множество дискуссий. Подневольный характер труда, плохие условия труда, устаревшее оборудование, отсутствие должного контроля за техникой безопасности, продолжительный рабочий день, завышенные нормы выработки, низкие зарплаты - имеет место быть и позволяет многим считать, что труд заключенных осуществляется с нарушением норм трудового законодательства. Правовое регулирование труда до сих пор остается нерешенным и болезненным для системы исполнения наказания.

Особую роль в формировании личности человека, в развитии всех его способностей и качеств принадлежит труду, практической деятельности. В процессе осуществления трудовой деятельности, у осужденных формируется и развивается трудолюбие, дисциплинированность, коллективная ответственность и др.

Воспитательная роль труда состоит в том, что он позволяет приобрести человеку определенные моральные качества, а также закрепляет их. При этом в процессе общественно полезного коллективного труда закрепляют-
Грунина Вероника Александровна

К.ю.н., дочент, Владимирский филиал Российской академии народного хозяйства и государственной службы при Президенте Российской Федерачии vgrun@rambler.ru

Ананьин Петр Александрович

К.ю.н., старший преподаватель, Владимирский юридический институт ФСИН России petron@rambler.ru

Аннотация. В статье рассматриваются проблемные вопросы организации и правового регулирования труда осужденных к лишению свободы. Анализируются проблемы, связанные с организацией труда, дается оценка возможности мотивации и организации эффективного использования трудовых ресурсов в лице осужденных в уголовно-исполнительной системе в условиях современной России.

Ключевые слова: осужденные, труд, право на труд, уголовно-исполнительная система.

ся и те новые качества, которые прививаются человеку по средством различных форм и методов воспитательного воздействия.

Необходимо отметить, что понятие «трудового воспитания» охватывает различные стороны практической, нравственной, и психологической подготовки осужденных к трудовой деятельности. Трудовое воспитание осужденных - это деятельность, направленная на вовлечение лиц отбывающих наказание в местах лишения свободы в трудовую деятельность, формирование у них психологической и практической готовности к труду, а также нравственных качеств и осознанной потребности трудиться.

Трактуя данное понятие, мы существенно ограничиваем содержание воспитательного потенциала труда: условия организации производства, характер трудовой деятельности, интересы и мотивы, формирующие отношение осужденных к труду и его результатам.

Важная роль в определении стратегии дальнейшего развития экономики УИС принадлежит Концепции реформирования уголовно-исполнительной системы (на период до 2020 года), поскольку в ней ставятся за- 
дачи дальнейшего совершенствования форм и методов производственно-хозяйственной деятельности и привлечения осужденных к труду[1].

Человек является социальным существом и субъектом общественно-исторической деятельности и культуры, чья жизнь, как правило, немыслима без его участия в труде[2]. Труд человека происходит во всех сферах жизни общества, включая и те, которые призваны принудительно сформировать у него уважительное отношение к обществу и труду.

Речь идет о лицах, осужденных по приговору суда к лишению свободы и привлекаемых в указанных местах к трудовой деятельности. При этом, как правило, труд является не способом самовыражения личности, которая реализует себя в данном качестве на основе конституционного принципа свободы труда[3], а средством исправления осужденных[4].

Данные обстоятельства воплощаются в особых приемах регулирования труда осужденных лиц, которые включаются в нормы действующего законодательства. В частности, к данным лицам не применим принцип запрещения принудительного труда[5].

Об эффективность функционирования пенитенциарной системы можно судить по различным формам реализации уголовных наказаний, количеству лиц не совершающих повторные преступления, а также по трудоустройству осужденных и овладению ими различными профессиями и навыками.

Особую роль в формировании личности человека, в развитии всех его способностей и качеств, принадлежит труду и практической деятельности. В процессе осуществления трудовой деятельности, у осужденных формируется и развивается трудолюбие, дисциплинированность, коллективная ответственность и др.

Важная роль труда состоит в том, что он позволяет приобрести человеку определенные моральные качества, а также закрепляет их. При этом в процессе общественно полезного коллективного труда закрепляются и те новые качества, которые прививаются человеку по средством различных форм и методов воспитательного воздействия.

Отбывание наказания в исправительном учреждении регулируется уголовно-исполнительным законодательством. Когда осуждённого привлекают к труду, кроме норм Уголовно-исполнительного кодекса в отношении него начинают действовать нормы трудового законодательства, но только в части, предусмотренной УИК РФ.
Ст. 103 УИК РФ указывает, что каждый осуждённый к лишению свободы обязан трудиться в местах и на работах, определяемых администрацией исправительных учреждений[4]. Это положение определяет природу отношений, порядок оформления на работу и право учреждения обеспечивать обязанность труда мерами дисциплинарного принуждения. Несмотря на то, что труд в исправительном учреждении обязателен под страхом наказания, он не является запрещённым Конституцией Российской Федерации «принудительным трудом».

По общему правилу, осуждённые не имеют права отказаться от работы, поэтому учреждение не обязано договариваться с ними об условиях работы и оплаты труда. Трудовой договор, обязательный в рамках трудового правоотношения, с осуждёнными не заключается.

Как правило, для лиц, осужденных к лишению свободы, труд является не правом, а обязанностью (ст. 103 УИК РФ); им запрещается прекращать работу для разрешения трудовых конфликтов (ч. 6 ст. 103УИК РФ) и устанавливаются иные ограничения в сфере осуществления трудовой деятельности, которая происходит исключительно в условиях центров трудовой адаптации осужденных и производственных (трудовых) мастерских исправительных учреждений, на федеральных государственных унитарных предприятиях уголовно-исполнительной системы и в организациях иных организационно-правовых форм, расположенных на территориях исправительных учреждений и (или) вне их, при условии обеспечения надлежащей охраны и изоляции осужденных (ч. 1 ст. 103 УИК РФ).

В отношении данной категории лиц устанавливаются и иные виды ограничений. Например, согласно ч. 3 ст. 107 УИК РФ в исправительных учреждениях на лицевой счет осужденных зачисляется независимо от всех удержаний (для возмещения расходов по их содержанию и удовлетворения всех требований взыскателей) не менее 25\% начисленных им заработной платы, пенсии или иных доходов.

Исключение составляют осужденные достигших возраста, дающего право на назначение страховой пенсии по старости, являющиеся инвалидами I и II группы, несовершеннолетние, беременные женщины и женщины, имеющие детей в домах ребенка исправительного учреждения, на лицевой счет которых после указанных выше удержаний зачисляется не менее 50\% начисленных им заработной платы, пенсии или иных доходов.

В связи с этим, начисленная осужденным заработная плата может составлять сумму, менее минимального размера оплаты труда (МРОТ) [6]. При этом данные ограни- 
чения в трудовых правах не нарушают общеустановленных конституционных прав граждан.

Как по этому поводу отметил Конституционный Суд РФ, установление удержаний из заработной платы, пенсий и иных доходов осужденных к лишению свободы для возмещения расходов по их содержанию - стоимости питания, одежды, коммунально-бытовых услуг и индивидуальных средств гигиены ежемесячно в пределах фактических затрат, произведенных в данном месяце,- не противоречит целям РФ как социального государства и обязательного труда как средства исправления осужденных.

В связи с чем, положения УИК РФ не могут расцениваться как нарушающие права осужденных лиц[7]. При этом нельзя сказать, что труд лиц, осужденных к лишению свободы не подпадает под сферу регулирования норм трудового законодательства.

Так, продолжительность их рабочего времени, правила охраны труда, техники безопасности и производственной санитарии (ч. 1 ст. 104 УИК РФ); право на оплату труда (ч. 1 ст. 105 УИК РФ); освобождение обучающихся осужденных от работы для сдачи экзаменов (ч. 3 ст. 112 УИК РФ) и т.п. устанавливаются в соответствии с трудовым законодательством РФ. Так, например, суды признают обоснованными применение органами государственной инспекции труда штрафных санкций в отношении администраций исправительных колоний, применяющих труд осужденных, по ст. 5.27 КоАП РФ[8] за нарушение законодательства о труде и об охране труда.

Более того, в УИК РФ прямо предусматривается, что труд лиц, осужденных к лишению свободы в колониях-поселениях регулируется законодательством РФ о труде. Исключение составляют правила приема на работу, увольнения с работы и перевода на другую работу (ч. 3 ст. 129 УИК РФ). Это подтверждается, в том числе материалами судебной практики.

В частности, судом признается обязанность администрации исправительных учреждений производить выплату заработной платы осужденным, отбывающим наказание в колониях-поселениях не реже, чем каждые полмесяца, т.е. по правилам ст. 136 ТК РФ.

Примечательно также и то, что некоторые осужденные судом к наказанию в виде лишения свободы, вправе заниматься трудовой деятельностью по своему желанию, т.е. труд для них выступает в качестве права, а не обязанности. Например, осужденные, достигшие возраста, дающего право на назначение страховой пенсии по старости, а также осужденные, являющиеся инвалидами I или II групп. В этом случае на них распространяется трудовое законодательство и законодательство о социаль- ной защите инвалидов (ч. 2 ст. 103 УИК РФ). Это означает, что их труд носит добровольный, а не принудительный характер, что отмечается в специальной юридической литературе[9]. В свою очередь, несовершеннолетние осужденные привлекаются к труду с учетом гарантий, предусмотренных трудовым законодательством РФ.

Следует отметить, что трудовая деятельность лиц, осужденных по приговору суда к уголовному наказанию, не связанному с лишением свободы, также регулируется нормами трудового законодательства РФ. Например, осужденных по приговору суда к обязательным работам (ч. 1 ст. 26 УИК РФ), исправительным работам (ч. 6 ст. 40 УИК РФ), в случаях отбывания наказания в виде ограничения свободы (ч. 5 ст. 50 УИК РФ) или осужденных к принудительным работам. Хотя и в данных случаях нормы трудового законодательства распространяются на данную категорию лиц с определенными изъятиями. Все это свидетельствует о том, что данные лица не могут не признаваться участниками трудовых и непосредственно связанных с ними отношений.

УИК РФ предусматривает, что отношения, возникающие при привлечении к труду данных категорий осуждённых, носят иную правовую природу - трудовую. Соответственно, отношения регулируются Трудовым кодексом с учётом запретов и ограничений, установленных УИК РФ. Если в УИК РФ нет специального порядка регулирования, то применяются нормы трудового законодательства. С такими осуждёнными должен составляться трудовой договор и оформляться трудовая книжка.

В судебной практике часто возникают споры по отнесению определённого временного периода к рабочему времени. При возникновении спора нужно исходить из того, что вывод осуждённого на производственный участок производится не для того, чтобы осуждённый там спал или пил чай, а для того, чтобы он исполнял трудовые обязанности.

Срочный вывод на работы в колонии обычно производится именно в связи с необходимостью произвести разгрузочные работы. Выполнение срочного заказа перечнем оснований к привлечению работника в праздничные дни не указано.

Работа в течение двух смен запрещается. Администрация учреждения может привлечь работника к сверхурочной работе в связи с неявкой сменщика на время не более 4-х часов. Администрация ИУ должна принять меры к замене любым другим работником в течение указанного времени.

Сверхурочная работа - это работа сверх продолжительности рабочего времени, ежедневной работы 
(смены), а при суммированном учёте рабочего времени - сверх нормального числа рабочих часов за учётный период. Администрация учреждения, привлекая осуждённого к работе в течение двух смен подряд, нарушает требования ч. 1 ст. 104 ТК РФ.

Как было указано Конституционным судом Российской Федерации в Определении от 18.12.2007 № 939-о-о «Об отказе в принятии к рассмотрению жалобы гражданина Абдужапарова Олега Абдулаевича», невыполнение или ненадлежащее выполнение осуждённым обязанности трудиться вследствие несоблюдения администрацией исправительного учреждения установленных законом условий и порядка привлечения его к труду не могут расцениваться как основания для наложения на него каких-либо взысканий.

Эта сентенция Конституционного суда открывает возможность оспорить дисциплинарное взыскание в связи с отказом от работы в течение двух смен подряд. Введённое Трудовым кодексом ограничение на работу в течение двух смен подряд основано на понимании того, что человек не может полноценно работать столь длительный срок. Чрезмерная усталость работника повышает, в том числе, опасность травматизма и ошибок, ведущих к аварийной ситуации[10].

Достаточно распространённым нарушением при суммированном учёте рабочего времени является необоснованное увеличение нормы часов рабочего времени. Нормальное число рабочего времени за учётный период определяется исходя из установленной для работников еженедельной продолжительности рабочего времени. Для примера подсчёта нормы можно взять норму часов работников, занятых обычный восьмичасовой рабочий день. Для работников, занятых неполный рабочий день или неполную рабочую неделю, нормальное число рабочих часов должно уменьшаться соответственно.

Осуждённые к лишению свободы имеют право на оплату труда в соответствии с законодательством Российской Федерации о труде. Невыплата заработной платы вообще, а в исправительном учреждении тем более,- грубейшее нарушение закона. В связи с тем, что трудовое законодательство предусматривает возможность отказа от выполнения работы, а уголовно-исполнительное запрещает осуждённому любой отказ от работы, в том числе для защиты своих трудовых прав, действия администрации учреждения можно квалифицировать как использование принудительного труда. Защитить осужденному себя в этой ситуации возможно либо написанием жалобы, либо в судебном порядке[10].

Целью системы наказания является исправление граждан, вставших на путь нарушения закона. Вместе с тем, в последнее время о труде как о средстве перевоспитания почти не говорят. Отчасти это правильно, потому что труд осуждённого в том виде, в котором он существует на сегодняшний день, это что угодно, но не средство воспитания. С другой стороны - совершенно напрасно, потому что успешные навыки труда подвигают человека к изменению поведения в нужное обществу направление. Невозможно ожидать положительного эффекта от трудовой деятельности в воспитательном процессе без построения механизма мотивации к труду.

Таким образом, можно отметить, что труд осужденных совместно с другими способами воспитательной работы является одним из основных средств воспитания и исправления. Причем труда осужденных следует рассматривать не только как процесс воспитания. Трудовая деятельность способствует развитию творческих способностей, чувства ответственности, повышает уверенность в себе.

Общественные отношения в сфере привлечения осужденных к труду объективно зависят от законов рынка и состояния экономики страны в целом. Принимая во внимание тот факт, что труд имеет исключительно высокий образовательный потенциал, мы считаем, что его обязательность по отношению к осужденным должна сохраняться как сейчас, так и в будущем.

Несмотря на то, что промышленные предприятия В местах лишения свободы находятся в чрезвычайно трудном положении. В настоящее время государство не в состоянии полностью финансировать ИУ, а это означает, что производство является единственным источником средств, который может помочь выжить[11].

Несомненно, промышленные предприятия УИС должны получать существенную государственную поддержку, то есть иметь финансовую поддержку, обеспечиваться государственным заказом, иметь сырье и материалы, хорошо развитые рынки сбыта товара. Такой подход к развитию производства в УИС все чаще предлагается учеными и практическими работниками, но для этого требуется соответствующее решение органов исполнительной власти и дополнительное государственное финансирование.

Подводя итог, необходимо сделать вывод о том, что трудовые отношения осужденных имеют свою специфику. В связи с этим они должны регламентироваться отдельными положениями трудового и уголовно-исполнительного законодательства Российской Федерации. Без внесения соответствующих изменений в Трудовой кодекс Российской Федерации, Уголовно-исполнительный кодекс Российской Федерации невозможно в полной мере обеспечить реализацию конституционных прав граждан на труд. 


\section{ЛИТЕРАТУРА}

1. 06 утверждении Концепции развития уголовно-исполнительной системы Российской Федерации до 2020 года: распоряжение Правительства Российской Федерации от 14.10.2010 № 1772-р // Собр. законодательства Рос. Федерации.— 2010.— № 43, ст. 5544.

2. Туленков А. А., Филиппова Е. О. Право осужденных к лишению свободы на труд на современном этапе развития уголовно-исполнительного законодательства // В сборнике: Scientific perspectives 2018. Сборник материалов XXXV Международной научно-практической конференции. 2018. С. 159-161.

3. Конституция Российской Федерации: принята всенародным голосованием 12.12.1993) (сучетом поправок, внесенных Законами РФ о поправках к Конституции РФ от 30.12.2008 № 6-ФК3, от 30.12.2008 № 7-ФК3, от 05.02.2014 № 2-ФК3, от 21.07.2014 № 11-ФКЗ) // Рос. газ.— 2009.— 21 янв.

4. Уголовно-исполнительный кодекс Российской Федерации от 8 января 1997 г. № 1-Ф3 (ред. от 27 декабря 2019 г. № 410-Ф3) // Собр. законодательства Рос. Федерации.— 1997.— № 2, ст. 198.

5. Трудовой кодекс Российской Федерации от 30 декабря 2001 г. № 197-Ф3 (ред. от 16 декабря 2019 г. № 502-Ф3 // Собр. законодательства Рос. Федерации. 2002. — № 1 (часть I), ст. 3; Конвенция № 29 Международной организации труда «0тносительно принудительного или обязательного труда» // Ведомости ВC СССР.—1956. — № 13, ст. 279.

6. 0 минимальном размере оплаты труда: федер. закон от 19 июня 2000 № 82-Ф3 (ред. от 27 декабря 2019 г.) // Собр. законодательства Рос. Федерации. 2000.— № 26, ст. 2729.

7. 06 отказе в принятии к рассмотрению жалоб гражданина Стягова Виктора Евгеньевича на нарушение его конституционных прав частью четвертой статьи 99 и статьей 107 Уголовно-исполнительного кодекса Российской Федерации, а также частью тринадцатой статьи 109Уголовно-процессуального кодекса Российской Федерации: Определение Конституционного Суда РФ от 27.10.2015 № 2369-0 // Документ опубликован не был. Доступ из СПС «Консультант Плюс»

8. Кодекс Российской Федерации $0 б$ административных правонарушениях от 30 декабря 2001 г. № 195-Ф3 (ред. 0 от 27 декабря 2019 г. № 450-Ф3) // Собр. законодательства Рос. Федерации. - 2002.— № 1 (часть I), ст. 1.

9. Зенина Н.В., Павлова Е. В., Строгович Ю. Н. Характеристика правового регулирования труда осужденныхклишению свободы // Российский следователь. 2015. - № 4. С. 42-47; Еремина С. Н. Возможность реализации права на труд осужденными к лишению свободы // Юридический мир. 一 2013. С. 58-61; Репринцев Д. Д. Правовое регулирование труда лиц, осужденных к лишению свободы // Трудовое прав0.— 2012.— № 5. С. $79-85$.

10. Справочник ОНК «Проведение мониторинга соблюдения прав осуждённых при привлечении их к труду». Пермь. 2016.

11. Чернышов И. Н. Цели труда в системе исправления осужденных // Человек: преступление и наказание.— 2016.— № 1 (92). С. 120 -126.

(c) Грунина Вероника Александровна ( vgrun@rambler.ru ), Ананьин Петр Александрович ( petron@rambler.ru ).

Журнал «Современная наука: актуальные проблемы теории и практики»

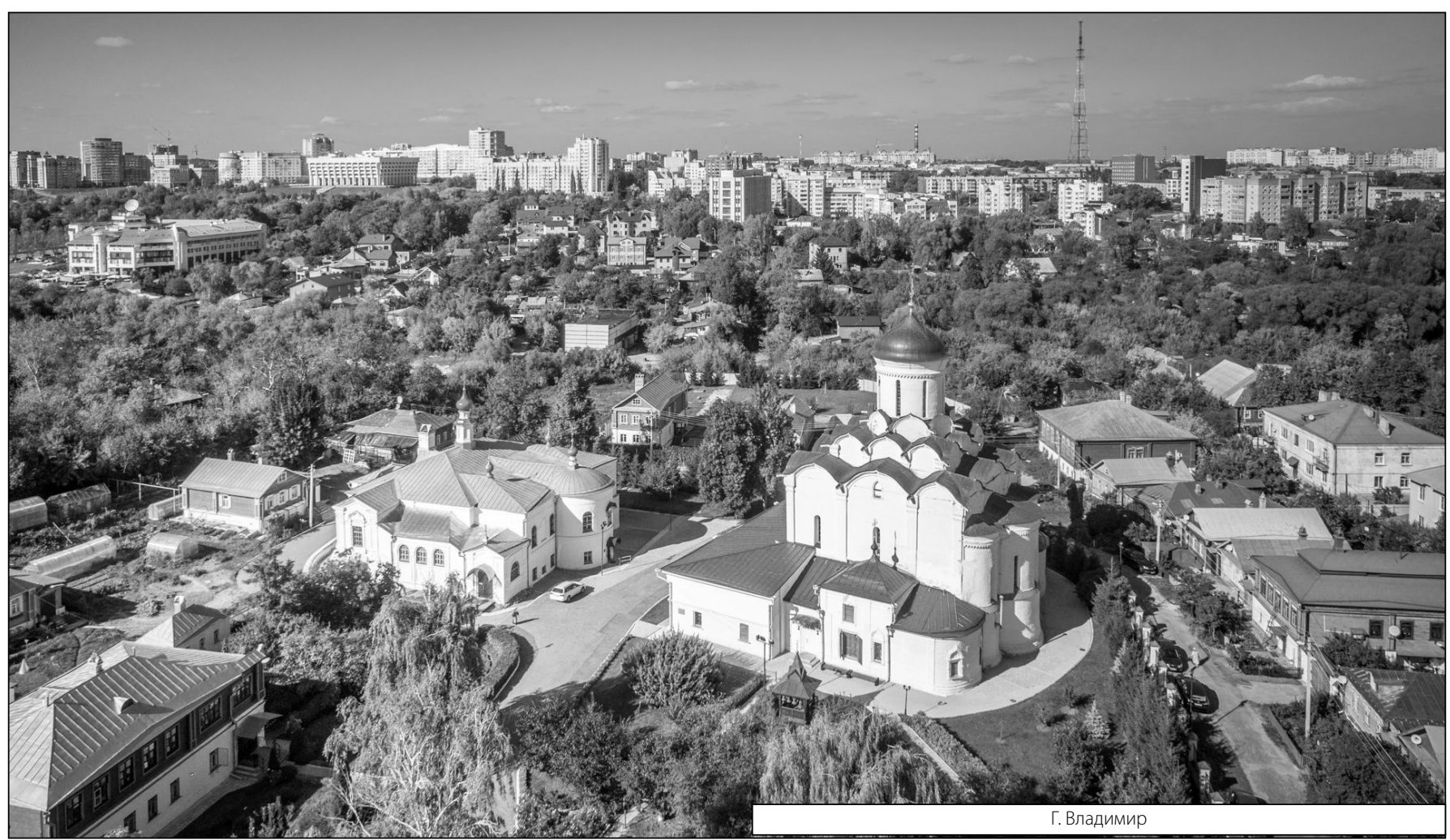

